\title{
Integrated Management System and Corporate Risk Management
}

\author{
Naqib Daneshjo ${ }^{1}$, Peter Malega ${ }^{2}$, Jakub Kóňa ${ }^{1}$, Barbara Barilová ${ }^{1}$ \\ ${ }^{1}$ University of Economics in Bratislava, Faculty of Commerce, Dolonozemská cesta 1, \\ 85235 Bratislava, Slovak Republic \\ ${ }^{2}$ Technical university of Kosice, Faculty of Mechanical Engineering, Letná 9, 04200 Košice, Slovak Republic
}

\begin{abstract}
The main motive for the integration of management systems should be to increase production efficiency by reducing losses due to overlapping resources of individual management systems running in parallel. In addition, by integrating, organisations can ensure the definition of unambiguous responsibilities and prevent problems at process interfaces as well as conflicting goals of individual management systems. The integration of management systems into one comprehensive and the implementation of an integrated system into the overall management of the organization would help to more effectively manage the risks associated with their business processes, resources and thus ensure prevention of these risks.
\end{abstract}

Keywords - management system, risk management, production system, ISO standard, business management

\section{Introduction}

Integrated management systems arose from the need of organisations to harmonise, combine or merge separately implemented management systems.

DOI: 10.18421/TEM104-26

https://doi.org/10.18421/TEM104-26

Corresponding author: Naqib Daneshjo,

Faculty of Commerce of the University of Economics in Bratislava, 85235 Bratislava 5, Slovak Republic.

Email: daneshj047@gmail.com

Received: 10 September 2021.

Revised: 16 October 2021.

Accepted: 23 October 2021.

Published: 26 November 2021.

(c) BY-NC-ND (c) 2021 Naqib Daneshjo et al; published by UIKTEN. This work is licensed under the Creative Commons Attribution-NonCommercial-NoDerivs 4.0 License.

The article is published with Open Access at www.temjournal.com
Despite the development of various IMS concepts, none of them was accepted as a generally valid model of the integrated management system, which would subsequently be standardised and issued as a globally valid ISO standard, according to which such a system could be certified as one separate integrated management system. Organizations are constantly exposed in the market environment to prove certificates of implementation and fulfilment of requirements of individual standardised management systems, it is, therefore, logical that integrated management systems were and still are created by merging and combining key elements of different specifically focused standardised management system models. New modern theories of managerial thinking and action place the application of the synergy effect in the first place. A manager or senior management is integrated into the integrated management system coming out of the principles of process management, based on continuous "management" of change (change management). As the organization grows, it constantly improves and standardises its processes, and from this point of view it can be characterized as a system of solid structure, declared powers and responsibilities, which considers cost minimization, high performance in transparent and optimised processes and flexible and secure information system to be the core of its success.

At present, the effort is generally being made to put significantly related systems on a common basis modern process management. Neither a functional and certified QMS nor a certified EMS always lead to increased productivity and competitiveness when understood as stand-alone and isolated systems. The current trend in corporate management is clearly the so-called "Comprehensive business integration", where already functional management systems are most often accessed by individual business subsystems, without which it is not possible to constantly increase the competitiveness of the organisation [1]. An integrated management system is an effective tool for creating a management system that takes into account not only the quality of 
products and services, but also the approach to the environment, safety and health at work and other important aspects for organisations. In addition, a systemic approach guarantees orientation in legislative requirements and their fulfilment, reduces administrative complexity and saves financial resources [2].

An integrated management system based on ISO standards for subsystems and EU regulations is advantageous to implement and integrate into a functioning business management system, which will become a functional management tool and ensure the prevention of all risks in the activities of the organization [4]. However, the nature of the individual management systems implies considerable compatibility between the relevant standards, as well as the common essence of operation on the principle of continuous improvement in terms of the P-D-C-A cycle, which allows the system to be extended to other aspects.

\section{Approaches to Risk Issues in Selected Areas}

We classify several types of corporate risks, resp. the risk groups shown in Figure 1. Some of these risks are described in more detail.

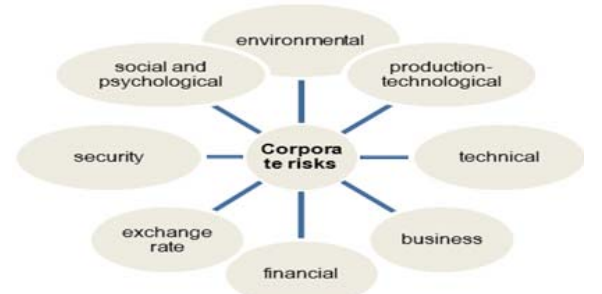

Figure 1. Classification of risks of the organisation according to their origin
Financial risks: Financial risks - they contain a wide range of cost risks caused by changes in cost data, which are mainly related to the growth of purchase prices of the given raw materials, energy. They also include inflation, monetary and budgetary risks, an important part of which also includes risks related to foreign trade activities (exchange rate risks affecting the income and costs of activities in foreign markets carried out in the currencies of their markets; risks related to the recovery of receivables...) and related foreign business (e.g., risks of conversion of achieved profit) [7].

Environmental risks: The quality of the environment is an important factor that affects human health and the quality of the ecosystem. Human activity is considered to be a serious cause of deterioration.

Risk assessment is an important process in a river basin that provides a better orientation on which monitoring issues to pay attention to or how to rank, present and use the results achieved. The process of environmental risk assessment (Figure 2.) in a river basin follows from the theory of risk management and can be divided into three basic parts [5]:

- Problem definition.

- Risk analysation.

- Risk characterization.

Other auxiliary assessment steps include: planning, risk management, monitoring.

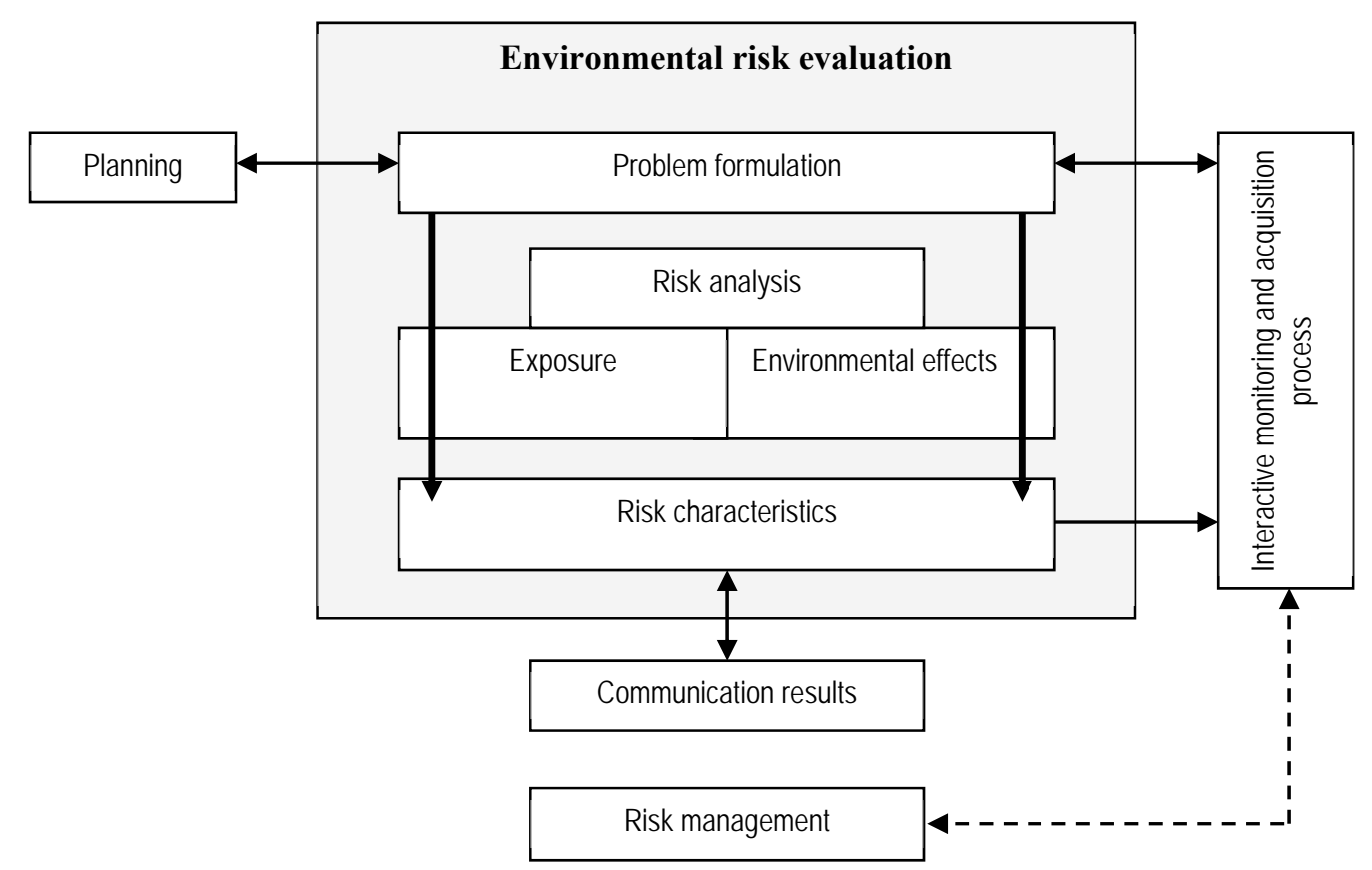

Figure 2. Environmental risk assessment scheme 
The environmental risk assessment process helps identify environmental problems, sets priorities, and provides a technical basis for regulatory action. At the same time, this process identifies existing risks or predicts the risks of stressors that do not yet manifest in the environment.

Technical risks: Uncertainty factors in the technical field include:

- Preparatory determination of parameters and purpose of the solution, preliminary increasing level of the new solution.

- Research, development and its completion on time.

- Speed of planning and construction.

- Timely completion of capital construction, trial operation.

- Reliability of activities and equipment.

- Several other factors.

Technical risks are mainly related to the realisation of the results of scientific and technical growth, they are most often associated with the research and development of new products and technologies. Technical risks are an increasingly serious problem for companies nowadays. Increasing production capacity, research results and their application to technical means, technologies, the use of automatic control systems, the volume of hazardous substances used in production and transport and a set of other factors have a negative impact on the company's safety level. Such risk is new in all areas of economic activity, categories of production processes, but also in services [10].
Technical risks are an increasingly serious problem today. Increasing production capacity, research results and their application to technical means, technologies, the use of automatic control systems, the volume of hazardous substances used in production and transport, and a set of other factors have a negative impact on society's safety level. Such risk is new in all areas of economic activity, categories of production processes, but also in services.

Transport, chemical production, and nuclear energy are also hazardous operations. In the individual categories of transport, both transport infrastructure and technologies are used, which are a source of risks that must be analysed and efforts must be made to reduce them. In the field of transport infrastructure, it is important to pay attention to the quality of transport routes, eliminate bottlenecks on roads, and ensure their systematic monitoring and maintenance, but the technical condition of transport and means of transport is a serious problem [3]. Transport technologies are determined by standards as well as internal regulations. Their serious problems are their preservation, but also the problem of applying the principles of occupational safety and the use of mandatory protective equipment. In this area, there is a need to create an effective control mechanism as the main tool for risk reduction [5], [8]. The basic algorithm of technical risk management consists of steps and is shown in Figure 3.

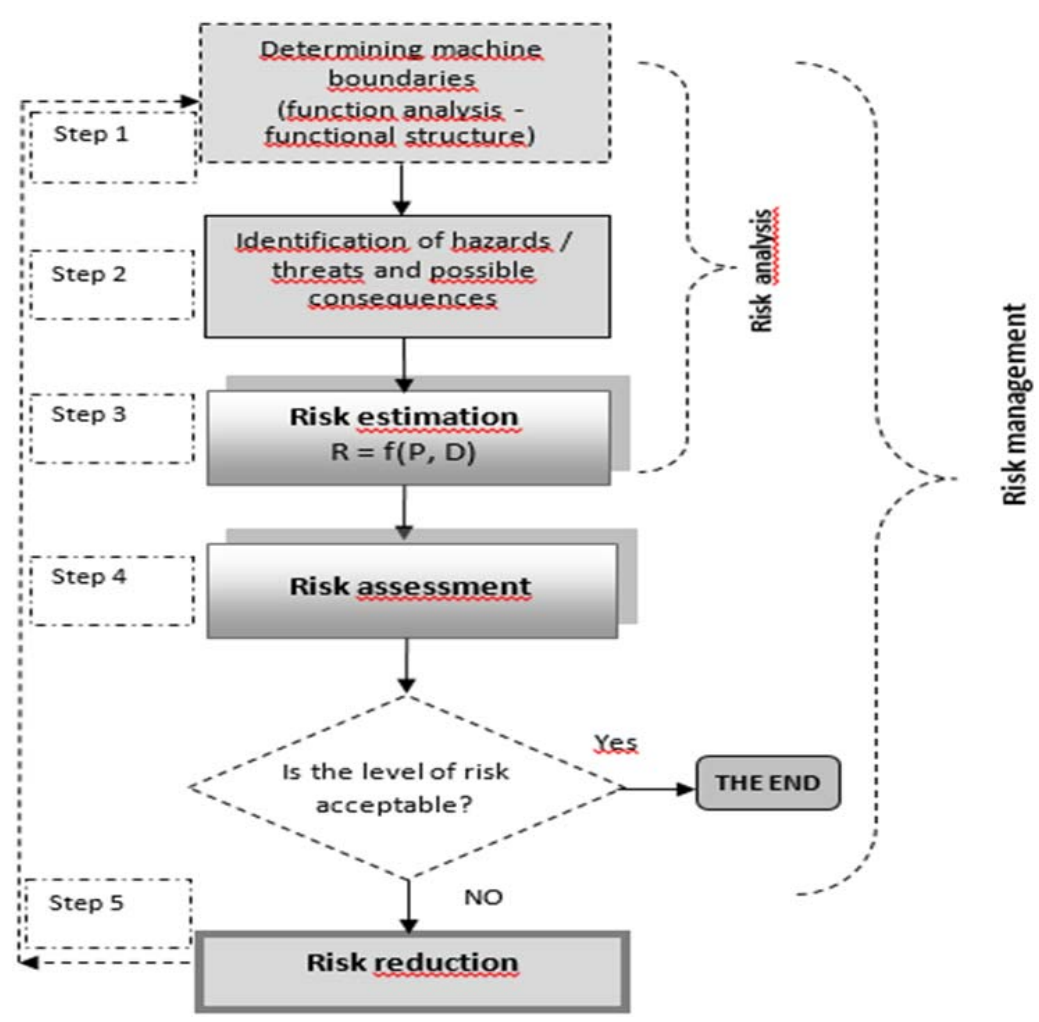

Figure 3. Risk management algorithm [9] 
Figure 4. shows the philosophy of technical risk management of critical processes using protective devices or additional protective devices according to
IEC 61508 (Risk reduction and integrated safety) taking into account the integrated safety requirements set out in the Machinery safety directive.

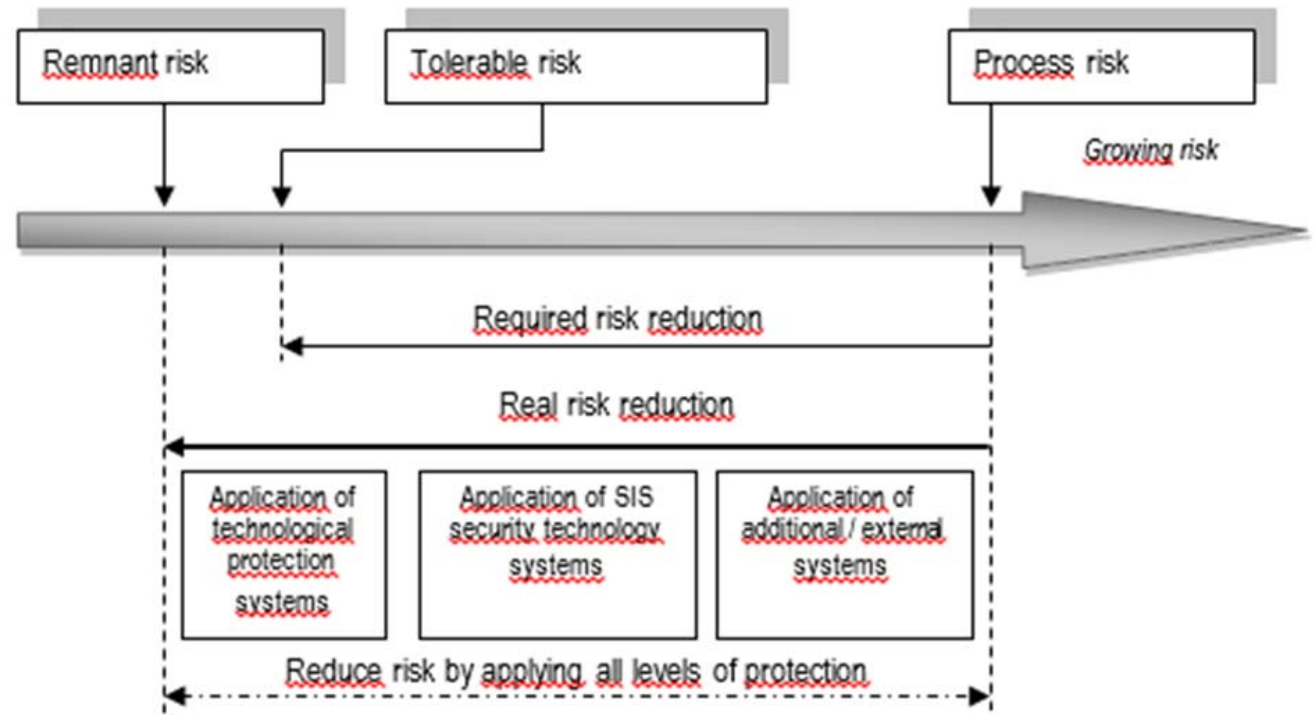

Figure 4. Risk reduction principle

3. Methodology for Risk Assessment and Management of the Integrated Management System

1. For effective business management, it is important to know the risks arising from its activities and processes, in an understandable expression of their extent. In the identification, analysis, evaluation, assessment and management of corporate risks, more exact methods are used today based on mathematical statistics, unclear sets, approaches to operational analysis, etc., which inherently assume a certain model of the occurrence of phenomena, i.e., they do not accept that these phenomena are exceptionally methods based on simulated or empirical scenarios. In principle, two basic approaches can be distinguished, namely:

2. Determining the threat to the integrated management system from the $\mathrm{N}$ mismatch and the period of its occurrence $\tau$ (in the fiscal year) by methods based on the theory of extremes, the theory of unclear sets, chaos theory, fractal theory, etc. According to the vulnerability of protected interests (quality, environment, health and safety, ...) in the company (process, technology, activity) to determine the total damage for non-compliance $\mathrm{N}$ (in monetary units) marked $\mathrm{S}$. Risk $\mathrm{R}$ is then given by the relationship.

$$
R=\frac{S}{\tau}
$$

Determination of the non-compliance scenario with the size of the largest expected noncompliance (it is possible to use the probable size of the expected non-compliance or the value of the normatively determined non-compliance or the least favourable non-compliance according to the requirements of the relevant ISO standards) and according to the data for the given company, resp. process to determine:

- According to the protected interests and their vulnerability to the impact in the scenario of non-compliance to determine the total damage of the company (process) in monetary units $\mathrm{S}$.

- According to expert data from databases or expert estimates to determine the frequency of occurrence of the largest expected discrepancy standardized for 1 change $f$.

$$
R=S * f
$$

For corporate management, we need to determine the integrated risk calculated according to relation (1) or (2), for all possible discrepancies that contribute to the disruption of the integrated management system [9]. To determine the integral risk of the system that reflects all possible non-conformities that contribute to the disruption of the integrated management system, the sum of the risks calculated for each noncompliance according to formula (1) or (2) may be used or the index method may be used as follows:

1. Let $\mathrm{i}=1,2, \ldots, \mathrm{n}$ be the number of protected interests of the monitored system. Assuming that each protected interest contains $s_{i}$ elements that make it up, it holds that:

$s_{i, j}$ is the $\mathrm{j}$-th element of the $\mathrm{i}$-th protected interest, i.e., $j=1,2, \ldots, s_{i}$ 
2. Let $h_{i, j}$ be the number of mismatches that threaten the element $s_{i, j}$, then it holds that:

i. $h_{i, j, k}$ is the $\mathrm{k}$-th mismatch in the $\mathrm{i}$-th protected interest for the $\mathrm{j}$-th element,

ii. i.e., it is possible to put $k^{\prime}=1,2, \ldots h_{i, j}$

Based on the estimation of the degree of vulnerability of specific elements of protected interests in individual disagreements, we determine the risk of the relationship:

$$
R_{i, j, k}=P_{i, j, k} \cdot D_{i, j, k}
$$

where $P_{i, j, k}$ is the probability of occurrence and $D_{i, j, k}$ is the impact. If we choose the risk scale as follows:

0 - insignificant risk, negligible

1 - Low risk, marginal

2- Acceptable risk below the applicable standards

3- Conditionally acceptable, i.e., tolerable risk that can be reduced by a conventional response system

4- Significant risk, i.e., risk above the limit of standards, which can be reduced by preparedness and a special response system

5 - Unacceptable risk

It is possible to determine the risk index $I_{i, j}$ for the $\mathrm{i}$-th protected interest and the $\mathrm{j}$-th element as a weighted average of individual indices for individual discrepancies

$$
I_{i, j}=\sum_{k=1}^{h_{i, j}} w_{i, j, k} \cdot I_{i, j, k}
$$

with the fact that:

$$
\sum_{k=1}^{h_{i, j}} w_{i, j, k}=1 \text {, }
$$

where $w_{i, j, k}$ is the weight of the risk index of the $\mathrm{k}-\mathrm{th}$ mismatch for the $i-$ th element of the $i-$ th protected interest. When the risk index of the $\mathrm{i}$-th protected interest is $I_{i}$, then

$$
I_{i}=\sum_{j=1}^{s_{i}} w_{i, j} \cdot I_{i, j}
$$

with the fact that:

$$
\sum_{j=1}^{s_{i}} w_{i, j}=1 .
$$

For the entire system, the risk index of all protected interests (quality, environment, information security, ...) is equal to

$$
I=\sum_{i=1}^{n} w_{i} \cdot I_{i}
$$

with the fact that:

$$
\sum_{i=1}^{n} w_{i}=1
$$

Whereas the values of the weights which indicate the significance of the corresponding indices can be determined in an analytical or expert manner.

The integral risk of the system, which expresses the probable magnitude of unacceptable impacts (losses, damages and injuries) of all possible discrepancies that contribute to the disruption of the integrated management system, we obtain using the relation (3). In this context, it should be recalled that for ease of understanding, it is useful to express the magnitude of the impact in monetary units.

Based on formulas (1) or (2), it is possible to identify the risks of individual management subsystems (quality, environment, safety, etc.) as well as the integrated management system as a whole. The integrated risk $R_{I N}$ is then given by the relationship.

$$
R_{I N}=\sum_{i=1}^{l} R_{i}
$$

Where $R_{i}$ for $i=1,2, \ldots, l$ are the risks of the subsystems. Considering the $\mathrm{n}$ possible discrepancies that contribute to the disruption of the integrated system, the total integrated risk $R_{C I N}$ of the occurrence of the discrepancy is determined by the relationship.

$$
R_{C I N}=\sum_{r=1}^{n} R_{I N_{r}}
$$

However, due to the interconnectivity of management systems, the integrated risk determined according to equations (10) and (11) is not entirely accurate and suitable for corporate governance, as it does not provide an estimate of the extent to the actual state of affairs, i.e., does not reflect the impact of the interconnections of the subsystems, which act in such a way that for each protected interest the impacts are direct, and the impacts caused by the interconnection of the subsystems.

Given that practical examples show that the properties of subsystems (resilience, vulnerability, ability to adapt and improve) in the monitored systems are procedural, technologically and timespecific, it is necessary to look for specific sector solutions, e.g., by field of economic activity (according to NACE codes) in the form of case studies.

Risk management procedure: There are no set rules for risk assessment, management and control. To make the procedure simple and systematic, a sequence of steps can be recommended, which is based on norms and is shown in Figure 5. [12]. 


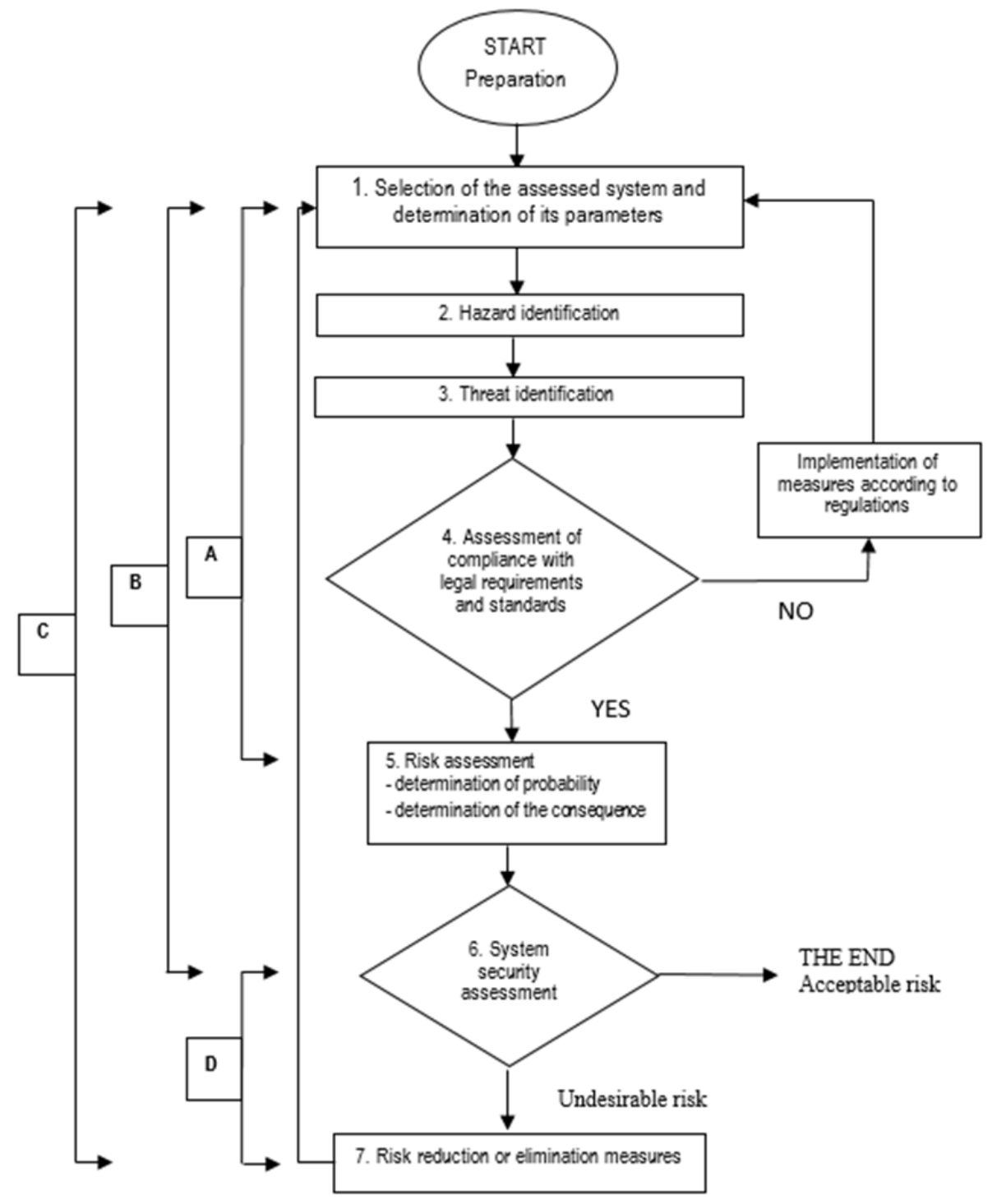

Where: A - risk analysis, B - risk assessment, $\mathrm{C}$ - risk management, D - risk control.

Figure 5. Risk management scheme [12]

\section{Economic Aspects of Risk Management}

In addition to probability, another key attribute of estimating the risk of an adverse event is determining the consequences of their occurrence. If we disregard such serious financially incalculable losses as the death of an individual or a group of people, it turns out that economic aspects play a significant role, especially in prevention and in providing the means to improve the quality of safety and reliability [10], [12]. The most accurate quantification of the costs resulting from the consequences of possible accidents, accidents, disagreements, or other adverse events can positively influence the decision-making process not only in matters directly focused on safety but also the effectiveness of management systems. The synergistic effect of the interaction of subsystems within the integrated management system will be manifested mainly if the analysis of risks (quality, environmental, safety, etc.) will be part of every decision-making process.
The quantification of financial losses on the property caused by an adverse event or disagreement is usually only a matter of accurate calculation. Determining e.g., cost of accidents at work and occupational diseases in practice seems to be a more complex problem [6].

The reduction of the quality of production and the consequent possible loss of goodwill or customer is also one of the possible consequences of the occurrence of an adverse event, deviation, discrepancy (e.g., work accident). Excluding a key expert from the work process can result in a series of other negative phenomena. In addition, negative phenomena (accidents, system failures) usually integrate several factors (qualitative, environmental, safety, economic, etc.).

As an example, some effective methods for estimating the costs of accidents at work and occupational diseases are given. Although at first glance these are specific methods (focused only on 
accidents at work), their principles are generalized to a comprehensive assessment of the costs associated with the occurrence of an adverse event. The basic premise of their accuracy is sufficient relevant data. However, these are often relatively easily available in integrated management systems. If we want to evaluate the costs of accidents at work (adverse events) within the company, it is appropriate to distinguish between two different aspects, namely:

- direct costs, which are also called visible costs,

- indirect costs, also called hidden or invisible costs.

Direct costs are to be understood as costs that are intended for persons affected by an accident and which are easier to identify and account for by insurance organizations. In general, they appear in the numerical statements of benefits determined for the calculation of the quotation of insurance against accidents at work and occupational diseases, which are transferred to the enterprise. The equivalent in the area of quantification of property losses is the size of non-life insurance premiums of relevant objects or equipment [11].

An accurate study of direct costs generally does not correspond to the amount of insurance fees or contributions set to cover the risk of accidents at work and occupational diseases.

A company that has no accidents (insured events) also pays listing fees (premiums), although reduced. In this case, however, we cannot talk about the direct costs of accidents, which do not actually exist, and therefore not even identify them with the amount of listing fees that the company pays. The identification of the direct costs of the accident with the amount of the listing fees has the advantage only in the simplicity of their estimation. However, this is also a major shortcoming, which has often made it difficult to research the economic aspect of security.

The exact direct costs of accidents at work and occupational diseases can be obtained by subtracting the reported rate from the "zero accident option" rate, multiplying by the total wage and dividing by 100 . This gives the exact value of direct costs for the company according to a given time interval [13]:

$$
P N=\frac{M\left(T_{a}-T_{o}\right)}{100}
$$

where:

$P N$ - direct costs,

$M$ - total wage, from which the listing fees are paid,

$T_{a}$ - announced rate,

$T_{o}$ - "zero accident rate" tariff.
We can do the same when estimating the direct costs of any undesirable insurance event. The current state of research, as well as the existing literature, does not provide strict principles for the valuation of indirect costs, which are not covered by insurance and are closely related to accidents or other adverse events. Their financial consequences, although less obvious and more difficult to account for than direct costs, quickly reach high values. These are, for example:

A) Labour costs caused by loss of time:

- Caused by the victim.

- Caused by other employees who have interrupted their work.

- Caused by personnel professionally involved in the accident.

- Caused by first aid members of the company's emergency services, by staff of independent medical services or by nurses and persons in charge of safety.

- Caused by staff assigned to repair the material or restore the victim's workplace,

- Caused by administrative staff entrusted with the drafting and sending of declarations, the resubmission of triplets, wage lists, the keeping of accident statistics, etc.

B) Costs related to the increase in personnel expenditure:

- Recruitment of a temporary or permanent alternate for the victim (selection procedure, administrative expenses, medical examination, training, including safety training).

- Additional wage paid to the accident victim in addition to the insurance company's cash benefits (collective agreement).

- Medical examination on return to work.

- Eventual payment of overtime hours for colleagues of the accident victim in order to make up for the time lost as a result of the accident.

- Compensation granted under the social title.

- Social assistance expenditures and interventions.

- Performance reduction.

- Replacement of the victim's personal equipment.

- Individual equipment of a newly employed person.

C) Costs related to material damage:

- Machinery, tools or other property of the enterprise.

- Loss of equipment, products or production raw materials. 
- The transformations that were necessary as a result of the accident.

- The cost of borrowing compensation for damaged equipment during its repair.

- Increase of insurance against damage to the equipment.

Very often, in studies on indirect costs, material damage is only taken into account if it is associated with bodily injury, but in the perspective of prevention, which seeks injury factors for staff, we should also address material damage that may have caused bodily injury, if anyone was there at the wrong time.

\section{Conclusion}

A modern, prosperous, competitive and sustainably developing European company, resp. the organisation of the third millennium is today unimaginable without the application of globally standardized and applied management systems, quality, environment, safety, social responsibility, etc., either individually or in the form of an integrated management system focused on comprehensively integrated risk management.

Risk management as a specific scientific discipline about the risks of their identification, analysis, assessment and management is now developing dynamically and is becoming an essential part of the implementation of diverse organisational activities, processes, technologies, but also socio-economic development in general.

Risk management is a procedure for purposeful management of existing risk through a system of measures aimed at eliminating risk or at least systematic and planned measures to reduce risk to the lowest possible level. It is a procedure aimed at permanent improving the level of health and safety, respectively at improving working atmosphere. Risk management includes a risk assessment algorithm and a decision about taking appropriate systemic measures.

Risk management is a key element of any strategic management of the organization. The organisation methodically addresses the risks associated with its activities in order to achieve permanent benefits within individual activities and in the entire portfolio of all activities.

\section{Acknowledgement}

This work has been supported by the Scientific Grant Agency of the Ministry of Education of the Slovak Republic (Project KEGA 032EU-4/2020 a KEGA 002TUKE-4/2020).

\section{References}

[1]. Badreddine, A., Romdhane, T. B., \& Amor, N. B. (2009). A new process-based approach for implementing an integrated management system: quality, security, environment. In Proceedings of the International MultiConference of Engineers and Computer Scientists (Vol. 2, No. 2, pp. 2-6).

[2]. Bookstaber, R. (1997). Global risk management: Are we missing the point?. Journal of Portfolio Management, 23, 102-108.

[3]. Frame, J. D. (2003). Managing risk in organizations: A guide for managers. John Wiley \& Sons.

[4]. Goossens, L., Cooke, R. M., \& Kraan, B. C. P. (1998). Evaluation of weighting schemes for expert judgement studies. PSAM4 proceedings, 1937-1942.

[5]. Hrubec, J., \& Virčíková, E. (2009). Integrovaný manažérsky systém (Integrated management system). Nitra, SUA in Nitra, 543.

[6]. Holdsworth, R. (2003). Practical applications approach to design, development and implementation of an integrated management system. Journal of hazardous materials, 104(1-3), 193-205.

[7]. Jørgensen, T. H., Remmen, A., \& Mellado, M. D. (2006). Integrated management systems-three different levels of integration. Journal of cleaner production, 14(8), 713-722.

[8]. Khan, F., Rathnayaka, S., \& Ahmed, S. (2015). Methods and models in process safety and risk management: Past, present and future. Process safety and environmental protection, 98, 116-147.

[9]. Pačaiová, H., Glatz, J., Kotianová, Z. \& Kacvinský, Š. (2011). Risk management 1 Košice: TU, SjF, 153 p., ISBN 978-80-553-0857-9.

[10]. Lesakova, D., \& Rehak, R. (2020). Empirical Exploration of Customer Management Focus and Its Impact on Business Performance 1. Ekonomicky Casopis, 68(7), 714-736.

[11]. Silver, B. (2011). BPMN 2.0 Handbook: Methods, Concepts, Case Studies and Standards in Business Process Management Notation. Future Strategies Inc., Book Division Lighthouse Point, Florida. pp.257. ISBN-13: 978-0-9819870-7-1.

[12]. Sinay, J. \& Majer, I. (2000). Risk Management II., Projekt Tempus - Phare IB_JEP-13406-98, SjF, Technical University of Košice, 1999-2000. ISBN 80-7099-567-X.

[13]. Wendling, R., Leseux, B. \& Sinay, J. (2000). Occupational Health and Safety Management, Project Tempus - Phare IB_JEP-13406-98, SjF, Technical University of Košice, 1999-2000.

ISBN 80-7099-578-5. 